\title{
Crescimento e produtividade do inhame cultivado entre faixas de guandu em sistema orgânico*
}

\author{
Fábio Luiz de Oliveira ${ }^{1}$; José Guilherme M Guerra ${ }^{2}$; Rodrigo M Junqueira ${ }^{3}$; Edmilson E da Silva ${ }^{3}$, Fábio \\ F de Oliveira"; José Antonio A Espindola ${ }^{2}$; Dejair L de Almeida ${ }^{2}$; Raul de LD Ribeiro ${ }^{5}$; Segundo \\ Urquiaga $^{2}$ \\ ${ }^{1}$ UNITINS, C. Postal 173, 77020-122 Palmas-TO; E-mail: fabioluiz@unitins.br; ²Embrapa Agrobiologia, C. Postal 74505, 23890-000
} Seropédica-RJ; E-mail: gmguerra@enpab.embrapa.br ${ }^{3}$ Mestrando na UFRRJ; ${ }^{4}$ Doutorando na UFRPE; ${ }^{5}$ UFRRJ, BR 465, km 07, 23851970 Seropédica-RJ; *Trabalho realizado com auxílio financeiro da FAPERJ e CAPES

\section{RESUMO}

Foi conduzido um experimento no município de Bom Jardim, Região Serrana do estado do Rio de Janeiro, visando a avaliar o crescimento e produtividade do inhame cultivado entre faixas de guandu, no sistema orgânico de produção. O delineamento experimental utilizado foi de blocos ao acaso, com quatro repetições e três tratamentos, que consistiram em cultivo entre faixas sem realização de poda; cultivo entre faixas com poda, com a biomassa mantida em cobertura do solo; e cultivo entre faixas com poda, com a biomassa removida da área. O sistema de cultivo entre faixas de guandu não podadas revelou-se promissor por promover proteção das plantas de inhame contra queimaduras foliares pela radiação solar, mantendo a mesma produtividade do sistema com faixas podadas. Além disso, revelou-se um método eficaz e de baixo custo para controle alternativo de plantas invasoras, prescindindo-se das capinas que oneram a produção orgânica do inhame, na qual o emprego de herbicidas não é admitido. A poda da faixa de guandu contribui para a melhoria da fertilidade do solo, pelo aporte de $6,58 \mathrm{t} \mathrm{ha}^{-1}$ de biomassa seca e 159 $\mathrm{kg} \mathrm{ha}^{-1}$ de $\mathrm{N}$ e ainda a ciclagem de $20 \mathrm{~kg} \mathrm{ha}^{-1}$ de P, $136 \mathrm{~kg} \mathrm{ha}^{-1}$ de $\mathrm{K}$, $64 \mathrm{~kg} \mathrm{ha}^{-1}$ de Ca e $16 \mathrm{~kg} \mathrm{ha}^{-1} \mathrm{de} \mathrm{Mg}$.

Palavras-chave: Cajanus cajan, Colocasia esculenta, adubação verde, taro.

\section{ABSTRACT}

Growth and productivity of the taro intercropped with pigeon pea hedgerows in organic system

Growth and productivity of taro intercropped with pigeon pea hedgerows in organic system under different management was tested in Bom Jardim, upland region of Rio de Janeiro State, Brazil. A completely randomized block design was used with four replicates. The treatments consisted of unpruned hedgerows; hedgerows pruned with the biomass maintained on the soil surface; and hedgerows pruned with the biomass removed from the experimental area. The unpruned hedgerows system was shown to be advantageous by protecting taro leaves against sun burning and keeping the same productivity of the hedgerows pruned system. In addition, it represented an effective way to control weeds, reducing manual labor and costs of organic taro production in which herbicides are not allowed. The legume hedgerows pruned promoted a significant input of organic matter and nitrogen (6.58 t of dry biomass ha $\mathrm{h}^{-1}$ and 159 $\mathrm{kg}$ of $\mathrm{N} \mathrm{ha}^{-1}$ ) and the recycling of other nutrients, like $20 \mathrm{~kg}$ of $\mathrm{P} \mathrm{ha}^{-1}$, $136 \mathrm{~kg}$ of $\mathrm{K} \mathrm{ha}^{-1}, 64 \mathrm{~kg}$ of Ca ha-1 and $16 \mathrm{~kg}$ of $\mathrm{Mg} \mathrm{ha}^{-1}$.

Keywords: Cajanus cajan, Colocasia esculenta, green manuring, taro.

(Recebido para publicação em 18 de fevereiro de 2004; aceito em 17 de novembro de 2005)

$\mathrm{O}$ inhame (Colocasia esculenta L. Schott) é uma espécie adaptada ao clima tropical, sendo pouco sujeita ao ataque de pragas e doenças. Seus rizomas apresentam alto valor nutritivo, com teores pronunciados de carboidratos e sais minerais (O'Hair \& Asokan, 1986). Essas características tornam o inhame bastante difundido entre os agricultores familiares, que procuram utilizar reduzida quantidade de insumos externos em suas unidades produtivas. Apesar dessa rusticidade, o inhame pode ter sua produtividade limitada por determinados fatores ambientais adversos. A incidência direta de raios solares pode ocasionar queimaduras foliares, enquanto a presença de plantas espontâneas nas áreas de cultivo promove competição por água e nutrientes. Por outro lado, existem relatos de que a aplicação de nitrogênio, sob forma de fertilizantes minerais sintéticos mostra baixa eficiência de uso, o que está associado a processos de perdas por lixiviação (Hartemink et al., 2000).

Sistemas orgânicos de produção baseiam-se em práticas agrícolas capazes de superar as limitações ambientais (Miyasaka et al., 2001). Dentre essas práticas, merece destaque o cultivo em aléias, que consiste no consórcio entre culturas, anuais ou perenes, com leguminosas arbóreas ou arbustivas, sendo estas últimas estabelecidas em faixas intercalares. Os múltiplos efeitos benéficos do cultivo entre faixas incluem: (a) formação de um microclima favorável ao desenvolvimento da cultura de interesse econômico, associado à interceptação da radiação solar pelo dossel das leguminosas (Altieri, 2002); (b) redução da população de ervas espontâneas, pela alteração de características físicas e químicas do solo e do próprio sombreamento da área cultivada (MacLean et al., 2003); (c) fornecimento de nitrogênio, proveniente da fixação biológica, liberado para as culturas de forma mais sincronizada com o crescimento, em comparação com aquele proveniente de fertilizantes minerais sintéticos (Crews \& Peoples, 2004).

Os efeitos dos cultivos em faixa para ganhos em produtividade tem apresentado variações dependendo das condições de clima e solo em que esse é implantado. Por isso, Lawson \& Kang (1990) sugerem que o sucesso dos sistemas de cultivo em faixa, depende de 
estudos realizados para estabelecer o manejo adequado a cada condição específica, que irá variar em função da cultura de interesse econômico, do clima e do solo da região.

O objetivo deste estudo foi avaliar o crescimento e produtividade do inhame cultivado entre faixas de guandu em sistema orgânico, nas condições edafoclimáticas da Região Serrana do Estado do Rio de Janeiro.

\section{MATERIAL E MÉTODOS}

O experimento foi implantado em unidade de produção comercial de inhame no município de Bom Jardim, Região Serrana do Estado do Rio de Janeiro. A unidade produtiva fica situada a $680 \mathrm{~m}$ de altitude, sendo o clima local caracterizado por temperaturas com média anual de $23^{\circ} \mathrm{C}$ e pluviosidade anual de $1275 \mathrm{~mm}$, apresentando, porém, acentuado decréscimo durante a estação de inverno.

O solo da área experimental foi classificado como Argissolo VermelhoAmarelo, anteriormente utilizado com pastagem mista de capim colonião (Panicum maximum), capim gordura (Melinis minutiflora) e braquiária (Brachiaria decumbens). Efetuou-se o preparo do solo manualmente com o auxílio de enxada, sendo posteriormente abertos os sulcos para estabelecimento das faixas de guandu. A análise do solo, coletado à profundidade de $0-20$ $\mathrm{cm}$, resultou: $\mathrm{pH}$ em água $=4,8 ; \mathrm{Al}=$ $1,2 \mathrm{cmol}_{\mathrm{c}} \mathrm{dm}^{-3} ; \mathrm{Ca}=0,5 \mathrm{cmol}_{\mathrm{c}} \mathrm{dm}^{-3} ; \mathrm{Mg}$ $=0,3 \mathrm{cmol}_{\mathrm{c}} \mathrm{dm}^{-3} ; \mathrm{K}=33 \mathrm{mg} \mathrm{kg}^{-1}$ e $\mathrm{P}=6$ $\mathrm{mg} \mathrm{kg}{ }^{-1}$.

Com base nesses resultados, fez-se aplicação de $5 \mathrm{t} \mathrm{ha}^{-1}$ de "cama" de aviário e de $1 \mathrm{t} \mathrm{ha}^{-1}$ de calcário dolomítico, além de uma adubação suplementar com $80 \mathrm{~kg}$ de $\mathrm{P}_{2} \mathrm{O}_{5} \mathrm{ha}^{-1}$ e $60 \mathrm{~kg}$ de $\mathrm{K}_{2} \mathrm{O}$ ha $^{-1}$, tendo como fontes, respectivamente, farinha de ossos e cinzas de lenha. O calcário foi aplicado a lanço, antes da abertura dos sulcos, enquanto o adubo orgânico e a mistura de farinha de ossos com cinzas foram dispostos ao longo dos sulcos de plantio do inhame.

$\mathrm{O}$ delineamento experimental utilizado foi de blocos ao acaso, com quatro repetições e três tratamentos, que consistiram em cultivo entre faixas de guandu sem poda; cultivo entre faixas com podas, com a biomassa mantida sobre o solo como adubo verde; e cultivo entre faixas com podas, com a biomassa removida da área experimental (controle). Este último tratamento adequar-seia a produtores que usam a biomassa do guandu para suprimento protéico na alimentação de animais, principalmente ruminantes, cujo esterco, por sua vez, é empregado na adubação de lavouras.

Foram estabelecidas quatro faixas de guandu com $5 \mathrm{~m}$ de comprimento por parcela, distanciadas de $4 \mathrm{~m}$ entre si. Essas faixas foram compostas por fileiras duplas de semeadura, espaçadas de 0,5 m, distribuindo-se 30 sementes por metro linear de sulco. As faixas formaram três aléias, nas quais foi plantado o inhame, sendo utilizada nas avaliações apenas a aléia central. Cada parcela comportou 64 plantas de inhame no espaçamento de $1,0 \times 0,3 \mathrm{~m}$, dispostas em quatro fileiras de plantio, sendo considerada como área útil aquela ocupada pelas 10 plantas centrais de cada uma das duas fileiras interiores. Foi utilizada a cultivar de guandu Caqui, de porte alto, semeada no dia 10 de maio de 2002 . A poda foi realizada em 15/01/03, aos 105 dias do plantio do inhame, quando o guandu atingiu cerca de $1,80 \mathrm{~m}$ de altura. O material vegetal resultante da poda foi transferido para as entrelinhas da cultura e mantido em cobertura sobre o solo ou retirado da área experimental, de acordo com o tratamento.

Estimativas da fixação biológica de nitrogênio pelo guandu e da contribuição para o fornecimento de $\mathrm{N}$ ao inhame foram feitas pelo método da abundância natural do isótopo ${ }^{15} \mathrm{~N}$ (Shearer \& Kohl, 1988). Para isto, utilizaram-se como plantas de referência as espécies picão-preto (Bidens pilosa) e trapoeraba (Commelina benghalensis), componentes da vegetação espontânea. Aos 30 dias após a realização da poda no guandu, foram determinadas a umidade volumétrica, temperatura do solo e incidência de luz com o auxílio de radiômetro. Foram procedidas avaliações mensais da população de plantas invasoras, computando-se o número de indivíduos e a biomassa total de cada espécie presente nas parcelas, e também, a incidência de queimaduras foliares pela ação direta da radiação solar, por meio da escala diagramática de Micherreff et al. (2000) modificada por Oliveira (2004), além da altura e a área foliar da planta, conforme Puiatti et al. (1992). Na colheita, realizada em 29/07/ 03 , quando os rebentos apresentavamse com tamanho comercializável, foi determinado o peso médio do rebento, o número de rebentos por planta, a produtividade em rebentos e a produtividade em rizomas centrais, além do teor de nitrogênio pelo método proposto por Bremner \& Mulvaney (1982) na folha mais desenvolvida e nos rizomas e rebentos.

\section{RESULTADOS E DISCUSSÃO}

A poda das faixas de guandu possibilitou um aporte de $159 \mathrm{~kg} \mathrm{~N}^{-1}$ ao sistema. Aproximadamente $45 \%$ do $\mathrm{N}$ contido na parte aérea podada do guandu foram oriundos da fixação biológica, permitindo estimar que em torno de 72 $\mathrm{kg}$ de $\mathrm{N} \mathrm{ha}^{-1}$ foram incorporados ao solo por este processo. A biomassa do guandu proporcionou, ainda, a ciclagem de, em média, $20 \mathrm{~kg} \mathrm{P} \mathrm{ha}{ }^{-1}, 136 \mathrm{~kg} \mathrm{~K} \mathrm{ha}^{-1}, 64$ $\mathrm{kg} \mathrm{Ca} \mathrm{ha}^{-1}$ e $16 \mathrm{~kg} \mathrm{Mg} \mathrm{ha}^{-1}$, bem como a incorporação de $6,58 \mathrm{t} \mathrm{ha}^{-1}$ de matéria orgânica ao solo.

A quantidade de potássio ciclada torna-se particularmente importante para a cultura do inhame. Nesse sentido, Puiatti et al. (1992) determinaram que o requerimento chega a $400 \mathrm{~kg}$ desse elemento, para alcançar-se produtividade de $60 \mathrm{t} \mathrm{ha}^{-1}$. Um aspecto considerado relevante foi de que, apesar do aporte de nitrogênio pelo guandu não ter afetado o conteúdo desse nutriente na folha mais desenvolvida do inhame, a cultura utilizou o $\mathrm{N}$ disponibilizado pela biomassa do guandu remanescente sobre o solo, perfazendo $26 \%$ do total analisado. Mesmo quando as faixas de guandu não receberam poda, verificouse que $12 \%$ do $\mathrm{N}$ contido na folha mais desenvolvida do inhame tinham essa origem (Tabela 1). Provavelmente, isto ocorreu, sobretudo, em decorrência da formação de liteira sob as faixas de guandu, proveniente da senescência natural de ramos finos e folíolos.

Ficou assim evidenciado que o guandu consorciado como adubo verde 
pode fornecer quantidade significante de nutrientes para o inhame. Apesar da reconhecida importância das leguminosas como fontes de nutrientes para culturas consorciadas (Kang \& Mulongoy, 1992), poucos estudos têm sido conduzidos visando a quantificar essa contribuição. Onim et al. (1990) detectaram aumentos dos teores de C orgânico, de $\mathrm{N}$, e do potencial de troca cationnica do solo, em longo prazo, com o uso de faixas de guandu e leucena no oeste do Quênia. Gichuru (1991) determinou que as faixas de guandu adicionavam à camada superficial do solo, em média, 135 $\mathrm{kg} \mathrm{N} \mathrm{ha}^{-1}, 15 \mathrm{~kg} \mathrm{P} \mathrm{ha}^{-1}$ e 4,5 t ha- de folhas secas. Esses resultados apontam para uma alta capacidade de enriquecimento do solo com nutrientes e matéria orgânica, gerando um gradiente de reserva a ser usado pelas culturas de interesse econômico dentro de um sistema rotacional (ICRAF, 1997). A entrada de $\mathrm{N}$ no sistema, oriundo do processo de fixação biológica, contido na biomassa podada do guandu, foi de aproximadamente $72 \mathrm{~kg} \mathrm{ha}^{-1}$, sendo maior que a exportada nos rizomas colhidos do inhame (Tabela 1), significando balanço positivo para esse elemento. Tratase, assim, de mais um indicativo para o sucesso da inclusão das faixas intercalares da leguminosa na produção orgânica do inhame, pois atende aos princípios agroecológicos, dentre os quais a redução da dependência por insumos externos, em busca da sustentabilidade.

Verificou-se, aos 135 dias de plantio do inhame, correspondendo a 30 dias após a poda do guandu, que a temperatura do solo descoberto (tratamento-controle) foi maior quando comparada com a dos demais tratamentos. As temperaturas mais baixas corresponderam às parcelas em que a biomassa podada do guandu foi mantida em cobertura ou quando as faixas de guandu não foram podadas (Figura 1B), com diferenças da ordem de, aproximadamente, $10^{\circ} \mathrm{C}$. Por outro lado, nas parcelas em que as faixas de guandu não receberam poda, houve aumento da umidade volumétrica em cerca de $30 \mathrm{~g}$ de água por $\mathrm{dm}^{3}$ de solo (Figura 1A).

Esses resultados demonstram os efeitos positivos da cobertura do solo, promovida pela biomassa mantida no sistema após a poda ou pela faixa não

Tabela 1. Teor de nitrogênio na folha-índice e percentual proveniente da fixação biológica (N-FB), teor de nitrogênio no rizoma e total exportado pelo inhame organicamente cultivado entre faixas de guandu submetidas a diferentes manejos. Bom Jardim, UFRRJ e Embrapa Agrobiologia, 2003.

\begin{tabular}{|c|c|c|c|c|c|}
\hline \multirow{3}{*}{$\begin{array}{l}\text { Manejo das } \\
\text { faixas de } \\
\text { guandu }\end{array}$} & \multicolumn{2}{|c|}{ Folha-índice } & \multicolumn{3}{|c|}{ Rizoma } \\
\hline & \multirow{2}{*}{ Teor $\mathbf{N}\left(\mathbf{g ~ k g}^{-1}\right)$} & \multirow{2}{*}{ N -FB (\%) - } & \multicolumn{2}{|c|}{ Teor $\mathbf{N}\left(\mathbf{g ~ k g} \mathbf{~ g}^{-1}\right)$} & \multirow{2}{*}{$\begin{array}{c}\text { N exportado } \\
\left(\mathrm{kg} \mathrm{ha}^{-1}\right)\end{array}$} \\
\hline & & & Rebento & Central & \\
\hline $\mathrm{PR}^{1}$ & $32,02 a^{2}$ & $12 \mathrm{~b}$ & $10,77 \mathrm{a}$ & $15,07 \mathrm{a}$ & $42,90 \mathrm{a}$ \\
\hline $\mathrm{PC}$ & $36,02 \mathrm{a}$ & $26 a$ & 11,25 a & $16,00 \mathrm{a}$ & 39,66 a \\
\hline NP & $33,59 \mathrm{a}$ & $9 \mathrm{~b}$ & $10,36 \mathrm{a}$ & $14,66 \mathrm{a}$ & $37,67 \mathrm{a}$ \\
\hline C.V. (\%) & 15,3 & 1,2 & 11,3 & 12,3 & 17,1 \\
\hline
\end{tabular}

${ }^{1} \mathrm{PR}=$ faixas podadas com material removido da área experimental; $\mathrm{PC}=$ faixas podadas com material mantido em cobertura do solo; $\mathrm{NP}=$ faixas não podadas.

${ }^{2}$ Médias de quatro repetições; médias seguidas da mesma letra, nas colunas, não diferem entre si pelo teste de Tukey $(\mathrm{p}<0,05)$.

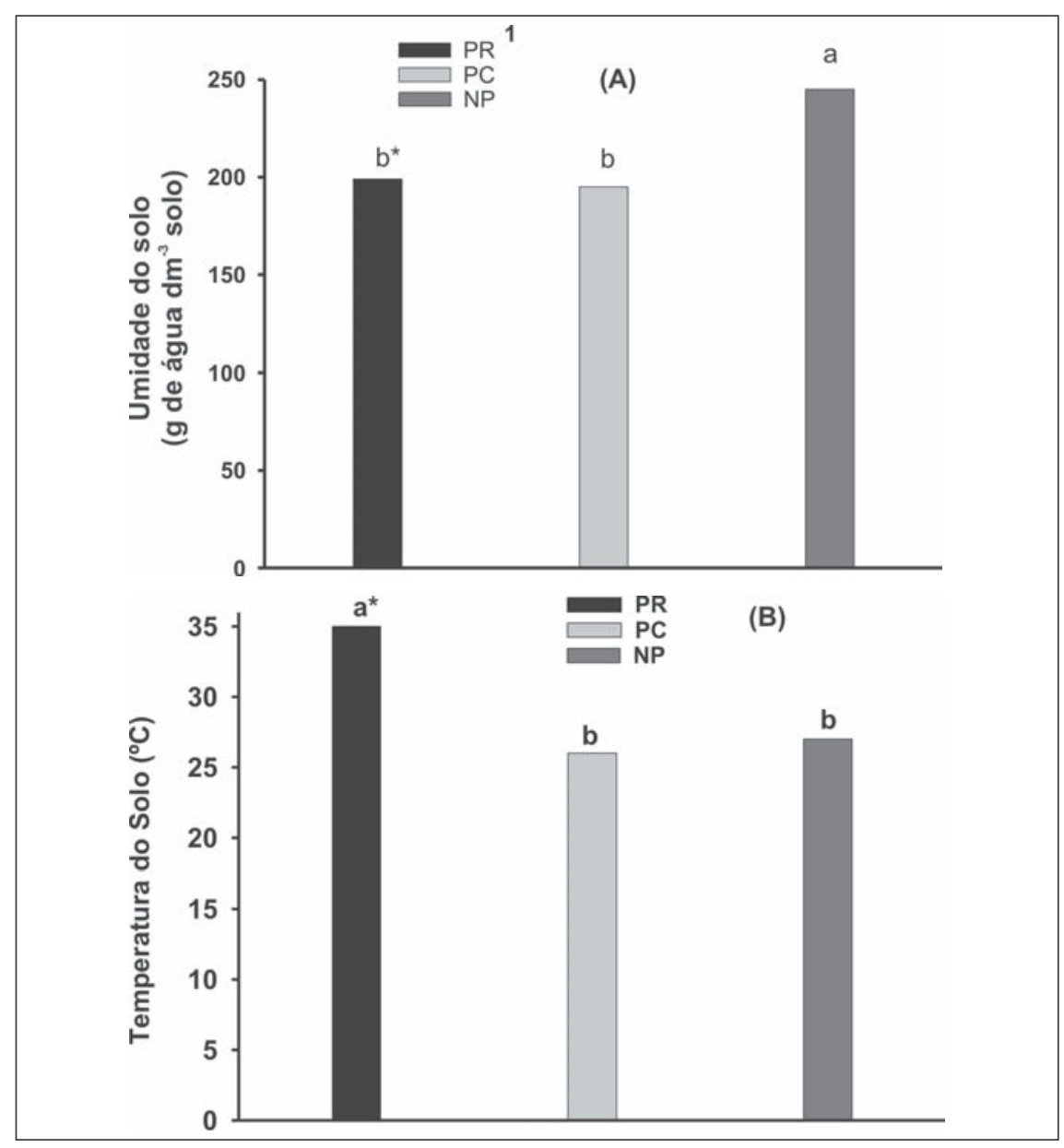

Figura 1. Umidade volumétrica (A) e temperatura média do solo (B), na camada de 0-20 $\mathrm{cm}, 30$ dias após a poda de faixas intercalares de guandu empregadas no cultivo orgânico de inhame. Bom Jardim, UFRRJ e Embrapa Agrobiologia, 2003.

* Colunas encimadas pela mesma letra representam valores médios que não diferem entre sí pelo teste de Tukey $(\mathrm{p}<0,05) .{ }^{1} \mathrm{PR}=$ faixas podadas com material removido da área experimental; $\mathrm{PC}=$ faixas podadas com material mantido em cobertura do solo; $\mathrm{NP}=$ faixas não podadas.

podada, para manutenção de menores temperaturas no solo; assim como da faixa não podada, promovendo maiores umidades. Resultados similares foram encontrados por Belsky et al. (1993) na savana do Kenya. Naquela região, solos cobertos por Acacia tortilis revelaram temperaturas reduzidas em até $6^{\circ} \mathrm{C}$, quando comparados a solos descobertos, na camada entre 5 e $10 \mathrm{~cm}$ de pro- 
Tabela 2. Biomassa seca da parte aérea da vegetação espontânea presente nas parcelas experimentais de inhame organicamente cultivado entre faixas de guandu submetidas a diferente manejo. Bom Jardim, UFRRJ e Embrapa Agrobiologia, 2003.

\begin{tabular}{|c|c|c|c|}
\hline \multirow{3}{*}{$\begin{array}{l}\text { Manejo das faixas de } \\
\text { guandu }\end{array}$} & \multicolumn{3}{|c|}{ Biomassa seca da vegetação espontânea ( $t$ ha $\left.^{-1}\right)$} \\
\hline & \multicolumn{3}{|c|}{ Dias após a poda do guandu } \\
\hline & 30 & 60 & 90 \\
\hline $\mathrm{PR}^{1}$ & $2,51 \mathrm{a}^{2}$ & $2,31 \mathrm{a}$ & $2,93 a$ \\
\hline PC & 1,98 a & $2,63 \mathrm{a}$ & $3,04 a$ \\
\hline NP & $0,95 \mathrm{~b}$ & $0,58 \mathrm{~b}$ & $0,93 b$ \\
\hline C.V. (\%) & 33,2 & 21,3 & 15,1 \\
\hline
\end{tabular}

${ }^{1} \mathrm{PR}$ = faixas podadas com material removido da área experimental; $\mathrm{PC}=$ faixas podadas com material mantido em cobertura do solo; $\mathrm{NP}=$ faixas não podadas.

${ }^{2}$ Médias de quatro repetições; médias seguidas da mesma letra, nas colunas, não diferem entre si pelo teste de Tukey $(\mathrm{p}<0,05)$.

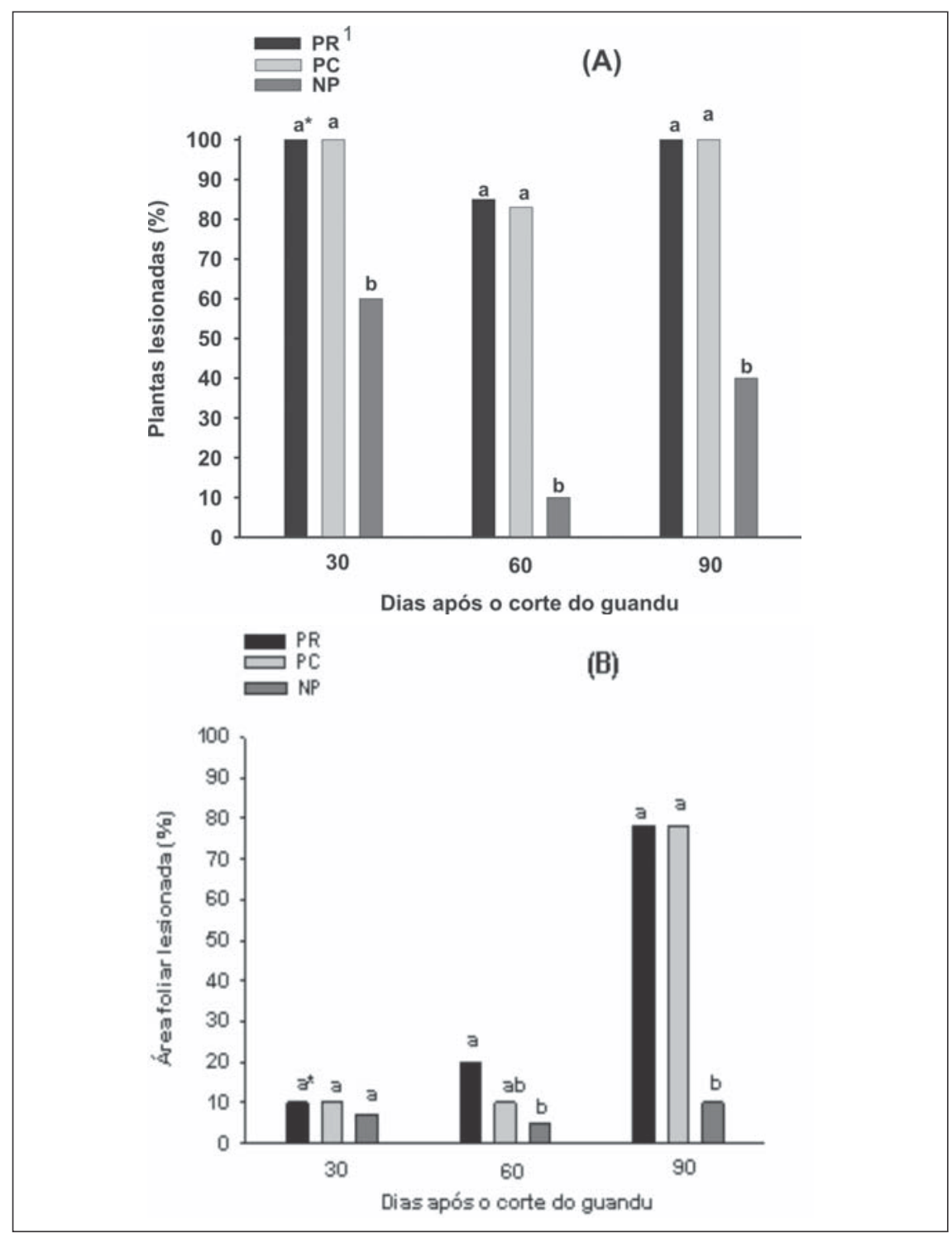

Figura 2. Percentuais de plantas (A) e de área foliar (B) lesionados pela incidência de raios solares, em parcelas experimentais de inhame organicamente cultivado entre faixas de guandu submetidas a diferente manejo. Bom Jardim, UFRRJ e Embrapa Agrobiologia, 2003.

* Colunas encimadas pela mesma letra representam valores médios que não se diferem pelo teste de Tukey $(\mathrm{p}<0,05) .{ }^{1} \mathrm{PR}=$ faixas podadas com material removido da área experimental; $\mathrm{PC}=$ faixas podadas com material mantido em cobertura do solo; $\mathrm{NP}=$ faixas não podadas. fundidade. As variações na temperatura do solo têm influência direta na evaporação de água do solo, o que afeta significativamente o crescimento das plantas cultivadas. Soman et al. (1986) verificaram reduções de 5 a $10^{\circ} \mathrm{C}$ na temperatura do solo, em áreas arborizadas, favorecendo o estabelecimento da cultura do milheto. Jonsson et al. (1997) também observaram redução da temperatura do solo sob condições de restrição de luz, influindo na demanda de água pelas plantas de milheto e atribuindo este fato à menor taxa de evaporação do solo, importante durante os períodos de seca. Prinz (1986) ressalta o ponto positivo do aumento da umidade no solo, pois pode significar um maior volume de água armazenada no solo, o que amenizaria a competição por água devida ao consórcio com a leguminosa.

As faixas de guandu não podadas exerceram supressão sobre as plantas invasoras, reduzindo a biomassa seca da população amostrada (Tabela 2), assim como demonstrado por outros autores (Anoka et al., 1991; Garrity, 1997) que pesquisaram diferentes modalidades de consórcios com espécies arbustivas ou arbóreas. Foram identificadas 10 espécies compondo a vegetação invasora, sendo predominantes o picão-preto (Bidens pilosa), a grama seda (Cynodon dactylon) e a trapoeraba (Commelina benghalensis), que juntas representaram cerca de $85 \%$ das amostras coletadas. Entretanto, no tratamento em que as faixas de guandu não foram podadas, somente foram encontradas duas delas, grama seda e trapoeraba, ocorrendo esta última em menor densidade populacional.

O controle de plantas invasoras na cultura de inhame é de acentuada importância, em virtude da arquitetura da planta e do ciclo relativamente longo, que a tornam mais suscetível à competição, principalmente em duas fases consideradas críticas: do início do crescimento até o quarto mês e durante a maturação, por ocasião do acúmulo de amido nos rizomas, quando há perda pronunciada de área foliar (Pimenta, 1993).

O uso do guandu como adubo verde, disposto em faixas intercalares, revelou-se eficaz no controle alternativo de plantas invasoras, prescindindo-se das capinas que oneram, de modo ex- 
pressivo, a produção orgânica do inhame. As faixas de guandu promoveram sombreamento parcial da cultura, reduzindo em até $60 \%$ a entrada de luz nas faixas não podadas, o que diminuiu significativamente a intensidade das queimaduras foliares pela radiação solar. Assim, com 90 dias a contar da poda do guandu e 210 dias do plantio do inhame, o sistema promoveu uma redução de $90 \%$ da área foliar lesionada e de $63 \%$ do número de plantas com sintomas (Figura 2).

A altura e a área foliar das plantas de inhame foram influenciadas pelo manejo das faixas de guandu. Quando essas faixas não receberam poda, as plantas apresentaram área foliar e altura mais elevadas (Tabela 3). Quanto maior a restrição à entrada de luz, mais a planta aumentava o limbo e alongava o pecíolo foliar (Tabela 3). Trata-se de uma resposta fisiológica à restrição de luz, ditada pela necessidade de manter a capacidade fotossintética, compensando deficiências de comprimento de onda no espectro, resultando na expansão da superfície de absorção de fótons (Taiz \& Zeiger, 1998). Oliveira (2004) constatou que a planta de inhame, sob condições de sombreamento, privilegia o investimento na formação da parte aérea em detrimento da subterrânea, ou seja, busca priorizar a capacidade de captação de luz e não a absorção de água e nutrientes.

Quanto aos parâmetros produtivos, houve influência do manejo adotado somente para peso médio do rebento, que apresentou aumento quando as faixas de guandu não foram podadas (Tabela 4). Em contra-partida, o número de rebentos por planta, a produtividade em rizomas centrais e a produtividade em rebentos não foram afetados pelos tratamentos. Young (1997) constatou que sistemas de cultivo em aléias apresentam resultados cumulativos e que as avaliações devem ser realizadas ao longo dos anos para caracterizar seus benefícios, inclusive relacionados a ganhos em produtividade das culturas de interesse econômico. Cabe ressaltar que a produtividade alcançada no presente experimento aproximou-se da média do estado do Rio de Janeiro, estimada em $15 \mathrm{t} \mathrm{ha}^{-1}$ (Silva \& Oliveira, 2002).

Portanto, pode-se destacar que o sistema de cultivo do inhame entre faixas de guandu proporciona proteção contra

Tabela 3. Altura e área foliar de plantas de inhame cultivado organicamente entre faixas de guandu submetidas a diferente manejo. Bom Jardim, UFRRJ e Embrapa Agrobiologia, 2003.

\begin{tabular}{|c|c|c|c|c|c|c|}
\hline \multirow{3}{*}{$\begin{array}{l}\text { Manejo das } \\
\text { faixas de } \\
\text { guandu }\end{array}$} & \multicolumn{6}{|c|}{ Dias após o corte do guandu } \\
\hline & \multicolumn{2}{|c|}{30} & \multicolumn{2}{|c|}{60} & \multicolumn{2}{|c|}{90} \\
\hline & $\begin{array}{l}\text { Altura } \\
(\mathrm{cm})\end{array}$ & $\begin{array}{c}\text { Área foliar } \\
\left(\mathrm{cm}^{2}\right)\end{array}$ & $\begin{array}{c}\text { Altura } \\
(\mathrm{cm})\end{array}$ & $\begin{array}{c}\text { Área foliar } \\
\left(\mathrm{cm}^{2}\right)\end{array}$ & $\begin{array}{c}\text { Altura } \\
\text { (cm) }\end{array}$ & $\begin{array}{l}\text { Área foliar } \\
\left(\mathrm{cm}^{2}\right)\end{array}$ \\
\hline$\overline{\mathrm{PR}^{1}}$ & $70,2 b^{2}$ & $782,4 \mathrm{~b}$ & $77,2 \mathrm{~b}$ & $563,3 \mathrm{~b}$ & $82,1 \mathrm{~b}$ & 299,4 b \\
\hline $\mathrm{PC}$ & $69,0 \mathrm{~b}$ & $894,1 \mathrm{~b}$ & $76,3 \mathrm{~b}$ & 517,6 b & $79,7 \mathrm{~b}$ & 308,2 b \\
\hline NP & 93,5 a & $1222,2 \mathrm{a}$ & $112,4 \mathrm{a}$ & $1060,2 \mathrm{a}$ & $106,7 \mathrm{a}$ & 800,6 a \\
\hline C.V. (\%) & 12,3 & 27,5 & 13,1 & 21,4 & 12,5 & 23,6 \\
\hline
\end{tabular}

${ }^{1} \mathrm{PR}=$ faixas podadas com material removido da área experimental; $\mathrm{PC}=$ faixas podadas com material mantido em cobertura do solo; $\mathrm{NP}$ = faixas não podadas.

${ }^{2}$ Médias de quatro repetições; médias seguidas da mesma letra, nas colunas, não diferem entre si pelo teste de Tukey $(\mathrm{p}<0,05)$.

Tabela 4. Número de rebentos por planta, peso médio do rebento, produtividade em rebentos e produtividade em rizomas centrais de inhame organicamente cultivado entre faixas de guandu submetidas a diferente manejo. Bom Jardim, UFRRJ e Embrapa Agrobiologia, 2003.

\begin{tabular}{lcccc}
\hline $\begin{array}{l}\text { Manejo das } \\
\text { faixas de } \\
\text { guandu }\end{array}$ & $\begin{array}{c}\mathbf{N}^{\circ} \text { de rebentos/ } \\
\text { planta }\end{array}$ & $\begin{array}{c}\text { Peso médio do } \\
\text { rebento }(\mathbf{g})\end{array}$ & $\begin{array}{c}\text { Produtividade } \\
\text { em rebentos } \\
(\mathbf{t} \text { ha-1) }\end{array}$ & $\begin{array}{c}\text { Produtividade } \\
\text { em rizomas } \\
\text { centrais (t ha-1 })\end{array}$ \\
\hline $\mathrm{PR}^{1}$ & $4,97 \mathrm{a}^{2}$ & $80,95 \mathrm{~b}$ & $13,53 \mathrm{a}$ & $10,23 \mathrm{a}$ \\
$\mathrm{PC}$ & $4,85 \mathrm{a}$ & $77,27 \mathrm{~b}$ & $12,87 \mathrm{a}$ & $8,76 \mathrm{a}$ \\
$\mathrm{NP}$ & $4,30 \mathrm{a}$ & $90,37 \mathrm{a}$ & $12,37 \mathrm{a}$ & $8,93 \mathrm{a}$ \\
\hline C.V. $(\%)$ & 15,3 & 11,5 & 17,2 & 18,5 \\
\hline
\end{tabular}

${ }^{1} \mathrm{PR}=$ faixas podadas com material removido da área experimental; $\mathrm{PC}=$ faixas podadas com material mantido em cobertura do solo; $\mathrm{NP}=$ faixas não podadas.

${ }^{2}$ Médias de quatro repetições; médias seguidas da mesma letra, nas colunas, não diferem entre si pelo teste de Tukey $(\mathrm{p}<0,05)$.

as queimaduras foliares provocadas pelo sol e apresenta-se como um método eficaz para controle da população de ervas espontâneas, prescindindo-se de capinas. Além disso, tal sistema de cultivo apresenta especial interesse para a produção orgânica da hortaliça, devido ao aporte significativo de matéria orgânica e nitrogênio, associado à ciclagem de outros macronutrientes.

\section{AGRADECIMENTOS}

À CAPES pela concessão da bolsa de estudos de doutoramento de Fábio Luiz de Oliveira.

\section{LITERATURA CITADA}

ALTIERI M. 2002. Agroecologia: bases cientificas para uma agricultura sustentável. Guaíba: Agropecuária, 592 p.

ANOKA UA; AKOBUNDU IO; OKONKWO SNC. 1991. Effects of Gliricidia sepium and Leucaena leucocephala on growth and development of Imperata cylindrica. Agroforestry Systems, 16: 1-12.
BELSKY AJ; MWONGA SM; DUXBURY JM. 1993. Effects of widely space trees and live-stock grazing on understory enviroments in tropical savannas. Agroforestry Systems, 24: 1-20.

BREMNER JM; MULVANEY CS. 1982. Nitrogen total. In: PAGE AL. (Ed.) Methods of soil analysis. 2ed. Madison: Soil Science Society of America, Part 2, p. 595-624.

CREWS TE; PEOPLES MB. 2004. Legume versus fertilizer sources of nitrogen: ecological trade-offs and human needs. Agriculture, Ecosystems and Environment, 102: 279-297.

GARRITY DP. 1997. Agroforestry innovations for Imperata grassland rehabilitation. Agroforestry Systems, 36: 1-274.

GICHURU MP. 1991. Residual effects of natural bush, Cajanus cajan and Tephrosia candita, on the productivity of acid soil in southeastern Nigeria. Plant and Soil, 134: 31-36.

HARTEMINK AE; JOHNSTON M; O'SULLIVAN JN; POLOMA S. 2000. Nitrogen use efficiency of taro and sweet potato in the humid lowlands of Papua, New Guinea. Agriculture, Ecosystems and Environment, 79: 271-280.

ICRAF - International Centre for Research in Agroforestry. 1997. Annual Report 1996. Nairobi, Nigéria, $220 \mathrm{p}$.

JONSSON K; ONG CK; ODONGO JCW. 1997. Tree crop intercropping in a parckland system with millet, néné and karité in Burkina Faso. Biology and Fertility of Soil, 23: 50-56. 
KANG BT; MULONGOY K. 1992. Nitrogen contribution of woody legumes in alley cropping systems. In: MULONGOY K; GUEYE M; SPENCER DSC. (Ed.). Biological Nitrogen Fixation and Sustainability of Tropical Agriculture. Chichester: JOHN WILEY \& SONS, p. 367-375.

LAWSON TL; KANG BT. 1990. Yield of maize and cowpea in alley cropping system in relation to available light. Agricultural and Forest Meteorology, 52: 347-357.

MacLEAN RH; LITSINGER JA; MOODY K; WATSON AK; LIBETARIO EM. 2003. Impact of Gliricidia sepium and Cassia spectabilis hedgerows on weeds and insect pests of upland rice. Agriculture, Ecosystems and Environment, 94: 275-288.

MICHERREFF SJ; MAFFIA LA; NORONHA MA. 2000. Escala diagramática para a avaliação da severidade da queima das folhas do inhame. Fitopatologia Brasileira, 25: 612-619.

MIYASAKA SC; HOLLYER JR; KODANI LS 2001. Mulch and compost effects on yield and corm rots of taro. Field Crops Research, 71: 101-112.

O'HAIR SK; ASOKAN MP. 1986. Edible aroids: botany and horticulture. Horticultural Reviews, 8: 43-99.
OLIVEIRA FL. 2004. Alternativas para o manejo orgânico do taro (Colocasia esculenta L. Schott) em condições edafoclimáticas no estado do Rio de Janeiro. 96 f. Tese (Doutorado em Fitotecnia) - Universidade Federal Rural do Rio de Janeiro, Seropédica- RJ.

ONIM JFM; MATHUVA M; OTIENO K; FITZHUGH HA. 1990. Soil fertility changes and response of maize and beans to green manures of leucaena, sesbania and pigeonpea. Agroforestry Systems, 12: 197-215.

PIMENTA DS. 1993. Crescimento e produção de inhame (Colocasia esculenta) com composto orgânico, amontoa e capina. 78 f. Dissertação (Mestrado em Fitotecnia) - Universidade Federal de Viçosa, Viçosa-MG.

PRINZ D. 1986. Increasing the productivity of smallholder farming systems by introduction of planted fallows. Plant Research and Development, 24: 31-56

PUIATTI M; GREEMAN S; KATSUMOTO R; FAVERO C. 1992. Crescimento e absorção de macronutrientes pelo inhame 'chinês' e 'japonês'. Horticultura Brasileira, 10: 89-92.
SILVA VV; OLIVEIRA FL. 2002. Tendências e potencialidades das culturas do inhame (Dioscorea sp.) e do taro (Colocasia esculenta) no Estado do Rio de Janeiro. In: SANTOS ES. et al. (Coord.) Simpósio Nacional sobre as culturas do Inhame e do Taro, II. EMEPA - Empresa Estadual de Pesquisa Agropecuária da Paraíba S.A., João Pessoa, Brasil, 1: 65-77.

SHEARER G; KOHL DH. 1988. Natural ${ }^{15} \mathrm{~N}$ abundance as a method of estimating the contribution of biologically fixed nitrogen to N2fixing systems: potencial for nonlegumes. Plant and soil, 110: 317-327.

SOMAN P; STOMPH TJ; BIDINGER F; FUSSEL LK. 1986. Improvement in stand establishment in pearl millet. In: INTERNATIONAL DROUGHT SYMPOSIUM: "Food Grain Production in the Semi-Arid Africa". 1986, Nairobi, Kenya, Proceeding..., Nairobi: OAU/STRC - SAFGRAD, Ouagadougou, Burkina Faso, p. 159-171.

TAIZ L; ZEIGER E. 1998. Phytochrome. In: TAIZ L; ZEIGER E. (Coord.) Plant Physiology. Sinauer Associates, Inc. Publ., Sunderland, Massachusetts, EUA. 2a ed., p. $483-516$.

YOUNG A. 1997. Agroforestry for soil management. CAB International, Wallingford: CAB International, $136 \mathrm{p}$. 